ASYMPTOMATIC

RHEUMATIC HEART

DISEASE

\title{
The challenge of screening for asymptomatic rheumatic heart disease in South Africa
}

\section{LiesI Zühlke* and Bongani M. Mayosi"}

"Western Cape Paediatric Cardiac Services, Red Cross War Memorial Children's Hospital and Tygerberg Hospital, Universities of Cape Town and Stellenbosch, Cape Town

"Department of Medicine, Groote Schuur Hospital and University of Cape, Cape Town

\section{Address for correspondence:}

Professor B.M. Mayosi

Department of Medicine

J Floor, Old Main Building

Groote Schuur Hospital

Observatory

7925

South Africa

Email:

bongani.mayosi@uct.ac.za

Acute rheumatic fever and rheumatic heart disease remain major features of medical practice in South Africa. The burden of rheumatic heart disease at the population level was estimated for the first time by Barlow and his team among 12000 school children in Soweto in 1971.(1) This auscultatory screening study of asymptomatic school children reported an overall prevalence of 6.9 per I 000, with a peak prevalence rate of 19.2/। 000 in older children. A decade later, there was a similar survey of I 000 school children in Inanda near Durban that found a lower prevalence of rheumatic heart disease of $1 / 1$ 000.(2) These findings led to calls for the establishment of a national programme for the prevention of rheumatic fever and rheumatic heart disease in South Africa. ${ }^{(1)}$ The government responded appropriately by declaring acute rheumatic fever and the initial diagnosis of rheumatic heart disease as notifiable conditions in 1979.(3) The first national guideline on the prevention of rheumatic fever and rheumatic heart disease at the primary care level was published in 1997.(4) These research, legislative, and policy making efforts have unfortunately met with little success mainly because of indifference and neglect on the part of medical practitioners and health administrators. ${ }^{(3,5)}$

\section{ABSTRACT}

Acute rheumatic fever and rheumatic heart disease remain common in the population of South Africa. A recent screening study of asymptomatic schoolchildren in Mozambique and Cambodia makes a compelling case for a shift in the approach to screening for rheumatic heart disease from auscultation to portable echocardiography. Rheumatic heart disease meets all the epidemiological criteria for screening in the South African population. The incorporation of echocardiographic screening programmes into the school health system and in antenatal clinics for the pre-symptomatic diagnosis of rheumatic heart disease could result in the reduction of morbidity and mortality through the early and wide application of secondary antibiotic prophylaxis. SAHeart 2009; 6:100-103

The Drakensberg Declaration, which arose out of the first All Africa Workshop on Rheumatic Fever and Rheumatic Heart Disease in October 2005, has led to renewed activity on the epidemiology and prevention of rheumatic heart disease in many parts of Africa. ${ }^{(6)}$ The focus of the action has been in four areas: awareness raising, conducting surveillance studies, advocacy, and promoting the establishment of national prevention programmes (the A.S.A.P. programme). ${ }^{(7)}$ The first important work to emerge in the post-Drakensberg era has been the echocardiographic screening study of school children in Mozambique and Cambodia. This study has shown that the prevalence of rheumatic heart disease by echocardiography is over 10 times higher than that detected by auscultation (i.e., 30.2/ I 000 vs. 2.2/l 000 in Mozambique). ${ }^{(8)}$ Almost all the cases of rheumatic heart disease detected in this and other screening studies were previously undiagnosed. These cases represent the tip of the iceberg of the burden of disease in the general population because cases in school children represent 15-20\% of all cases in the population. ${ }^{(9)}$ 
A series of echocardiographic screening studies confirm that rheumatic fever and rheumatic heart disease are of sufficient importance to warrant the urgent attention of the international public health and research communities. ${ }^{(10-12)}$ These echocardiographic screening studies have major implications for clinical and public health practice in South Africa. These data raise questions on whether screening for asymptomatic rheumatic heart disease is required, how it should be conducted, what diagnostic criteria should be used, and the cost-effectiveness of screening for asymptomatic rheumatic heart disease.

\section{RATIONALÉ FOR SCREENING ASYMPTOMATIC PEOPLE FOR RHEUMATIC HEART DISEASE}

For a disease to be suitable for screening as a tool for prevention, it must satisfy the following conditions: (I) there must be evidence of a significant burden of disease, (2) the condition must have an initial latent stage, (3) which can be detected by simple, accessible, sensitive and specific tests, and (4) there must be evidence that early intervention improves prognosis. It can be argued that rheumatic heart disease meets all the criteria for screening in many developing countries such as South Africa. There is evidence that the condition may affect up to $3 \%$ of school children; that large numbers of pre-symptomatic cases exist, that portable echocardiography is a sensitive tool for screening; and that the early introduction of penicillin prophylaxis prevents recurrent attacks of acute rheumatic fever. ${ }^{(1,8,13)}$

A 2002 report from a paediatric cardiology workshop highlights the belief among clinicians that South Africa continues to experience a high burden of cases of symptomatic rheumatic heart disease. ${ }^{(5)}$ Recent reports show that rheumatic heart disease is present in $1 \%$ of pregnant patients presenting to tertiary centres and is associated with high maternal morbidity and mortality and poor foetal outcomes. ${ }^{(14,15)}$

Clinical and echocardiographic screening studies indicate that the overwhelming majority of cases (over 85\%) with definite rheumatic heart disease are asymptomatic. ${ }^{(1,8,11,12)}$ These observations indicate that the disease has a pre-symptomatic stage that can be detected by portable echocardiography and penicillin prophylaxis is available to prevent recurrent attacks of rheumatic fever and potentially ameliorate the development of chronic rheumatic heart disease. There is therefore a strong case to be made for the screening of the general population for rheumatic heart disease in South Africa and other countries where the disease remains endemic.
WHAT IS THE APPROPRIATE METHOD FOR SCREENING ASYMPTOMATIC PEOPLE FOR RHEUMATIC HEART DISEASE?

Several studies present a compelling argument for the use of portable echocardiography as the screening test of choice for asymptomatic individuals who are at high risk of rheumatic heart disease, as opposed to screening by cardiac auscultation. ${ }^{(8,11)}$ If clinical diagnosis had been relied upon in the Mozambique study, approximately $90 \%$ of echocardiographically detected cases would have been missed.(8,10) In the Mozambican study, clinical examination underdiagnosed rheumatic heart disease more than 10 fold, whereas in the Tongan study, the opposite held in that junior auscultators overestimated rheumatic heart disease. ${ }^{(8,11)}$ This variability in the performance of cardiac auscultation in screening probably reflects differences in the clinical skill and experience of the clinicians, a factor that is not likely to improve in an era of over-reliance on technology and tests in clinical medicine.

The time has come to replace the stethoscope with portable cardiac ultrasound in screening for rheumatic heart disease. ${ }^{(16-18)}$ The cost of portable ultrasound equipment is falling and the technical capability of these devices is improving. There is therefore a need to increase the availability and use of portable echocardiography in endemic regions of the world. In addition the feasibility of training a large number of local healthcare workers in basic echocardiography to screen for rheumatic heart disease should be investigated.

\section{DIAGNOSTIC CRITERIA FOR RHEUMATIC HEART DISEASE IN ASYMPTOMATIC INDIVIDUALS}

Until now, the diagnosis of rheumatic heart disease in asymptomatic individuals has been based on the detection of pathological murmur in combination with typical echocardiographic morphological changes and functional abnormalities (e.g., Doppler regurgitation or stenosis) of the heart valves. The patients with no history of acute rheumatic fever nor a clinically audible murmur but who have typical structural and functional abnormalities of rheumatic heart disease on echocardiography are regarded as probable rheumatic heart disease. Individuals with isolated Doppler regurgitation on echocardiography with no history of rheumatic fever, no audible murmur, and no structural valve abnormality are regarded as possible rheumatic heart 
disease. The natural history of possible and probable rheumatic heart disease (i.e., subclinical rheumatic heart disease) is not known. (17) In addition, it is not known whether penicillin prophylaxis is indicated in subjects with subclinical rheumatic heart disease. ${ }^{(19)}$ The World Health Organisation, however, recommends antibiotic prophylaxis for those with "significant" subclinical rheumatic mitral regurgitation, who are defined on the basis of the following echocardiographic criteria: $(I)$ the presence of a colour jet of more than I centimetre in length, (2) that is evident in at least two imaging planes, (3) with the mosaic jet having a peak velocity of greater than 2.5 metres per second, and that the Doppler signal is holosystolic.(19,20) The WHO criteria differentiates physiological from pathological regurgitation, but these criteria do not cover many of the morphological changes seen in chronic rheumatic heart disease. Investigators in the A.S.A.P. programme propose to use an amalgamation of the WHO criteria with the findings of Viyashlaskmi and others to detect definite, probable and possible disease on screening echocardiograms. ${ }^{(20)}$ This approach allows the classification of cases into definite, probable and possible rheumatic heart disease using criteria that consider all possible functional and structural abnormalities that are associated with rheumatic fever and rheumatic heart disease (Tables I and 2).

\section{COST-EFFECTIVENESS OF SCREENING FOR ASYMPTOMATIC RHEUMATIC HEART DISEASE}

There is good evidence that primary prevention (i.e., treatment of suspected streptococcal pharyngitis with penicillin) and secondary prophylaxis (i.e., regular intramuscular penicillin injections) for rheumatic fever are cost-effective interventions for the control of rheumatic heart disease. ${ }^{(13,21)}$ Secondary prophylaxis is best delivered as part of a register-based control programme, providing education and enabling better clinical follow-up.(22) It is not known, however, whether the use of portable echocardiography to screen asymptomatic people in rheumatic heart disease-endemic regions is cost-effective. ${ }^{(23)}$ The major costs are related to staff, equipment, and other health service costs of community-based screening. One way of reducing the costs related to screening may be to integrate rheumatic heart disease screening with the existing school health system and antenatal care services for school children and pregnant women, the two high-risk groups who may be targeted initially.
TABLE I: Proposed echocardiographic diagnostic criteria for rheumatic heart disease used in screening studies of asymptomatic participants without a history of rheumatic fever

\section{Definite RHD}

Significant mitral stenosis (mean gradient: $>4 \mathrm{mmHg}$ )

Significant structural and/or functional changes involving both mitral and aortic valves, i.e., multiple valve disease

\section{Probable RHD}

Significant structural and functional changes involving either mitral or aortic valves, i.e., single valve disease

\section{Possible RHD}

Isolated structural $\mathrm{OR}$ functional changes involving either mitral or aortic valve

TABLE 2: Definitions of Structural and Functional changes in rheumatic heart disease

\begin{tabular}{l|l|}
\hline \hline \multicolumn{2}{|c|}{ Definitions } \\
\hline $\begin{array}{l}\text { Significant structural changes: } \\
\text { Thickness of mitral and aortic leaflets } \\
\text { greater than 4mm }\end{array}$ & $\begin{array}{l}\text { Significant functional changes: } \\
\text { Significant mitral regurgitation: } \\
\text { defined as a mitral regurgitant jet at } \\
\text { least I cm from the coaptation point } \\
\text { of the valve leaflets, seen in two planes, } \\
\text { high velocity (mosaic pattern) and }\end{array}$ \\
$\begin{array}{l}\text { Increased echogenicity of submitral } \\
\text { structures }\end{array}$ & $\begin{array}{l}\text { persisting throughout systole. Addi- } \\
\text { tional changes that may be present } \\
\text { include multiple regurgitant jets and/or }\end{array}$ \\
\hline $\begin{array}{l}\text { Rheumatic nodules giving a beaded } \\
\text { appearance }\end{array}$ & $\begin{array}{l}\text { a posterolaterally-directed jet } \\
\text { Prolapse of mitral, aortic or tricuspid }\end{array}$ \\
\hline valves & $\begin{array}{l}\text { Significant aortic regurgitation: } \\
\text { defined as an aortic regurgitant jet at } \\
\text { least I cm from the coaptation point } \\
\text { of the valve leaflets, of high velocity } \\
\text { (mosaic pattern) and seen in two }\end{array}$ \\
\hline $\begin{array}{l}\text { Chordal tears } \\
\text { planes }\end{array}$ \\
\hline $\begin{array}{l}\text { Elbow or dog leg deformity of the } \\
\text { anterior mitral valve leaflet. }\end{array}$ & \\
\hline $\begin{array}{l}\text { Fixed or markedly restricted motion } \\
\text { of the posterior mitral leaflet }\end{array}$ & \\
\hline
\end{tabular}

\section{CONCLUSION}

It is clear from the new evidence on the superior performance and high yield of echocardiographic screening of rheumatic heart disease in high-risk communities that we cannot continue with "business as usual" in the management of rheumatic heart disease in South Africa. (24) First, healthcare practitioners in South Africa need to be reminded that rheumatic fever is a notifiable condition and be encouraged to develop registrybased follow-up clinics for their patients with rheumatic heart 
disease. ${ }^{(3,22)}$ These two simple interventions would go a long way towards documenting the burden and temporal trends of acute rheumatic fever and rheumatic heart disease in the country, and ensuring that all patients with the disease are in secure secondary prophylaxis programmes. There are too few cases that are reported, which has contributed in part to the neglect of rheumatic heart disease as an important public health problem. ${ }^{(3,25)}$ Second, we need to consider the incorporation of echocardiographic screening for rheumatic heart disease in the schools and antenatal clinics of South Africa. The auscultatory and echocardiographic findings of screening can be transmitted to clinical cardiology centres for reporting by trained staff. The possibility of using technologists, nurses or even local community health care workers to perform a focused echocardiogram with specialised staff reviewing these echocardiograms should be explored. ${ }^{(23)}$ With the shortages in trained staff in all strata of healthcare, we need to develop innovative and creative strategies for the implementation of effective screening programmes in resource-poor settings. The A.S.A.P. programme provides an evidence-based framework for building a national programme of prevention of rheumatic heart disease in South Africa and other African countries. ${ }^{(7)}$ Finally, prospective studies are required to evaluate the natural history and management of subclinical rheumatic heart disease, and to explore costeffective strategies for the screening of rheumatic heart disease in the general population of South Africa.

\section{REFERENCES}

I. McLaren MJ, Hawkins DM, Koornhof HJ, et al. Epidemiology of rheumatic heart disease in black school children of Soweto, Johannesburg. Br Med J. 1975;3:474-8.

2. Maharaj B, Dyer RB, Leary WP, et al. Screening for rheumatic heart disease amongst black schoolchildren in Inanda, South Africa. J Trop Pediatr. 1987;33:60- I.

3. Nkgudi B, Robertson KA, Volmink J, et al. Notification of rheumatic fever in South Africa - evidence for underreporting by health care professionals and administrators. S Afr Med J. 2006;96:206-8.

4. National Guidelines on the Primary Prevention and Prophylaxis of Rheumatic Fever and Rheumatic Heart Disease for Health Professionals at Primary Level. Pretoria: Department of Health; 1997.

5. Robertson KA, Volmink JA, Mayosi BM. Lack of adherence to the national guidelines on the prevention of rheumatic fever. S Afr Med J. 2005;95:52-6.

6. Mayosi B, Robertson K, Volmink J, et al. The Drakensberg declaration on the control of rheumatic fever and rheumatic heart disease in Africa. S Afr Med J. 2006;96(3 Pt 2):246.

7. Robertson KA, Volmink JA, Mayosi BM. Towards a uniform plan for the control of rheumatic fever and rheumatic heart disease in Africa - the Awareness Surveillance Advocacy Prevention (A.S.A.P.) programme. S Afr Med J. 2006;96 (3 Pt 2):24I-5.
8. Marijon E, Ou P, Celermajer DS, et al. Prevalence of Rheumatic Heart Disease Detected by Echocardiographic Screening. N Engl J Med. 2007 August 2. 2007;357(5):470-6.

9. Carapetis JR, Steer AC, Mulholland EK, et al. The global burden of group A streptococcal diseases. Lancet Infect Dis. 2005 2005/ I 1;5( I I):685-94.

I0. Carapetis JR. Rheumatic heart disease in developing countries. N Engl J Med. 2007;357:439-41.

11. Carapetis JR, Hardy M, Fakakovikaetau T, et al. Evaluation of a screening protocol using auscultation and portable echocardiography to detect asymptomatic rheumatic heart disease in Tongan schoolchildren. Nat Clin Pract Cardiovasc Med. 2008:5:41।-7.

12. Sadiq M, Islam K, Abid R, et al. Prevalence of rheumatic heart disease in school children of urban Lahore. Heart. 2009 March 1, 2009;95(5):353-7.

13. Manyemba J, Mayosi BM. Intramuscular penicillin is more effective than oral penicillin in secondary prevention of rheumatic fever--a systematic review. S Afr Med J. 2003;93:212-8.

14. Nqayana T, Moodley J, Naidoo DP. Cardiac disease in pregnancy. Cardiovasc J Afr. 2008;| 9:| 45-5।.

15. Soma-Pillay P, MacDonald AP, Mathivha TM, et al. Cardiac disease in pregnancy: a 4-year audit at Pretoria Academic Hospital. S Afr Med J. 2008;98:553-6.

16. Damasceno A, Cotter G, Dzudie A, et al. Heart Failure in Sub-Saharan Africa: Time for Action. J Am Coll Cardiol. 2007;50 (17): 1 688-93.

17. Damasceno A, Cotter G, Dzudie A, et al. Early detection of rheumatic heart disease and prevention of heart failure in sub-Saharan Africa.(letter) J Am Coll Cardiol. 2008;5।:1 126.

18. Marijon E, Tafflet M, Jouven $X$. Time to use ultrasound and not stethoscopes for rheumatic heart disease screening. Nat Clin Pract Cardiovasc Med. 2008;5:EI-E3.

19. Marijon E, Celermajer DS, Jouven X. Management of patients with subclinical rheumatic heart disease. International Journal of Cardiology. In Press.

20. Vijayalakshmi IB, Mithravinda J, Deva AN. The role of echocardiography in diagnosing carditis in the setting of acute rheumatic fever. Cardiol Young. 2005 Dec; 15( I047-95। I VI - I5 IP - 6 DP - 2005 Dec):583-8.

21. Robertson KA, Volmink JA, Mayosi BM. Antibiotics for the primary prevention of acute rheumatic fever: a meta-analysis. BMC Cardiovasc Disord. 2005 May 31;5(1):11.

22. McDonald M, Brown A, Noonan S, et al. Preventing recurrent rheumatic fever: the role of register-based programmes. Heart. 2005 September I, 2005;9I(9): $1|3|-3$.

23. Marijon E, Ou P, Celermajer DS, et al. Echocardiographic screening for rheumatic heart disease. Bull World Health Organ 2008;86:84.

24. Veasy LG, Tani LY, Minich L. The logic for extending the use of echocardiography beyond childhood to detect subclinical rheumatic heart disease. Cardiol Young. 2009; 19:30-3.

25. Watkins DA, Zuhlke LJ, Engel ME, et al. Rheumatic fever: neglected again. Science. 2009:324:27.

26. Vijayalakshmi IB, Mithravinda J, Deva AN. The role of echocardiography in diagnosing carditis in the setting of acute rheumatic fever. CTY. 2005 Dec ।;15(6):583-8. 